\title{
DE LO MATERIAL E INMATERIAL: EL TESORO DE ALISEDA COMO PARADIGMA DE LA INVESTIGACIÓN ARQUEOLÓGICA
}

\author{
ON MATERIAL AND IMMATERIAL ISSUES: THE ALISEDA \\ TREASURE AS A PARADIGM OF THE ARCHAEOLOGICAL \\ RESEARCH
}

\author{
Alicia PEREA CAVEDA \\ Museo Arqueológico Nacional
}

\section{Resumen}

Reflexiones autocríticas en torno al concepto de "Tesoro" como objeto de deseo, como hallazgo arqueológico y como objeto de estudio, a lo largo de la historia de la investigación en la península Ibérica.

Palabras clave: Oro, Ocultamiento, Tesoro, Historia de la Arqueología, Península Ibérica.

\begin{abstract}
Self-critical considerations on the concept of "Treasure" as an object of desire, as an archaeological find and as an object of study, throughout the history of research in the Iberian Peninsula.

Key words: Gold, Hoard, Treasure, History of Archaeology, Iberian Peninsula.
\end{abstract}

\section{1. "EN BUSCA DEL ARCA PERDIDA"}

Entre los héroes de ficción que más éxito han tenido en la producción cinematográfica de los últimos treinta años está Indiana Jones, franquicia de Georges Lucas que contó con el buen oficio del director Steven Spielberg y la acertada interpretación de Harrison Ford. Acorde con su profesión -arqueólogo y profesor de universidad- y su entorno histórico -años treinta del siglo pasado-, el objetivo principal del personaje es encontrar tesoros perdidos y objetos seudohistóricos mencionados en 
textos y manuscritos de dudosa procedencia, siempre en beneficio del museo de alguna universidad estadounidense -la potencia dominante- que se constituye en la institución financiadora y la justificación ética de todas sus empresas. No existen leyes de protección de patrimonio, ni aduanas, ni obligaciones fiscales o morales que pongan coto a su actividad internacional. En definitiva, cumple punto por punto la práctica de una arqueología objetual, decimonónica, colonialista, acientífica, ahistórica y depredadora. No debe extrañarnos puesto que de estos objetos están llenos los grandes museos occidentales, que visitamos con placer y admiramos con envidia, porque, nos dicen, representan una parte importante de la historia de la humanidad. El recorrido ético y estético entre Indiana Jones y la actualidad es bastante corto. A pesar del tiempo transcurrido y los avances científicos, tecnológicos y metodológicos, sigue existiendo una arqueología objetualista y depredadora, una mala praxis como en cualquier otra actividad profesional.

No sólo el cine de aventuras, los museos también tienen su responsabilidad en la manera de presentar el objeto arqueológico ante el público. Todos hemos visitado alguna vez una Sala del Tesoro en este o aquel museo -por ejemplo, The Gold Room en el Hermitage, o The Treasury en el Museo Nacional Irlandés-; todos hemos ojeado libros con el título Tesoros del Metropolitan Museum o Tesoros del Louvre, que adornan convenientemente nuestras estanterías cogiendo polvo. Y nosotros los arqueólogos hemos bautizado demasiadas veces con el apelativo de tesoro hallazgos a los que no les corresponde tal denominación, con el objetivo de atraer la atención, dar visibilidad o buscar financiación extra para futuras investigaciones. En definitiva, el término tesoro ha sido devaluado, desfigurado y manipulado por el uso y abuso de los propios arqueólogos. Es verdad que de las cinco acepciones de la palabra, la RAE propone la siguiente: "Conjunto escondido de monedas o cosas preciosas, de cuyo dueño no queda memoria", lo cual en muchos casos es verdad, pero en otros no. Lugares comunes como "Tesoro de Tutankamón" han hecho fortuna, y a nadie se le ocurre decir el "Ajuar funerario de Tutankamón", que es lo que es.

La circunstancia concreta del hallazgo de objetos arqueológicos valiosos ha sido, en muchos casos, determinante a la hora de rodearlos de un aura de misterio, aventura e incluso inverosimilitud, que se asocia con naturalidad a la idea de "hallazgo del tesoro". Es público y notorio que el Tesoro de Guarrazar (Perea, 2001a) se encontró gracias a la necesidad fisiológica perentoria de una mujer durante un viaje en carreta entre Toledo y Guadamur, un día de lluvia de 1858. El Tesoro de Villena (Soler, 1965) se extrajo de la tierra una noche cerrada de otoño de 1963 a la luz de una antorcha para evitar un posible expolio (Fig. 1). Pero lo más frecuente es el hallazgo fruto de labores agrícolas, como el Tesoro de Torredonjimeno (Perea, 2009); durante la construcción 


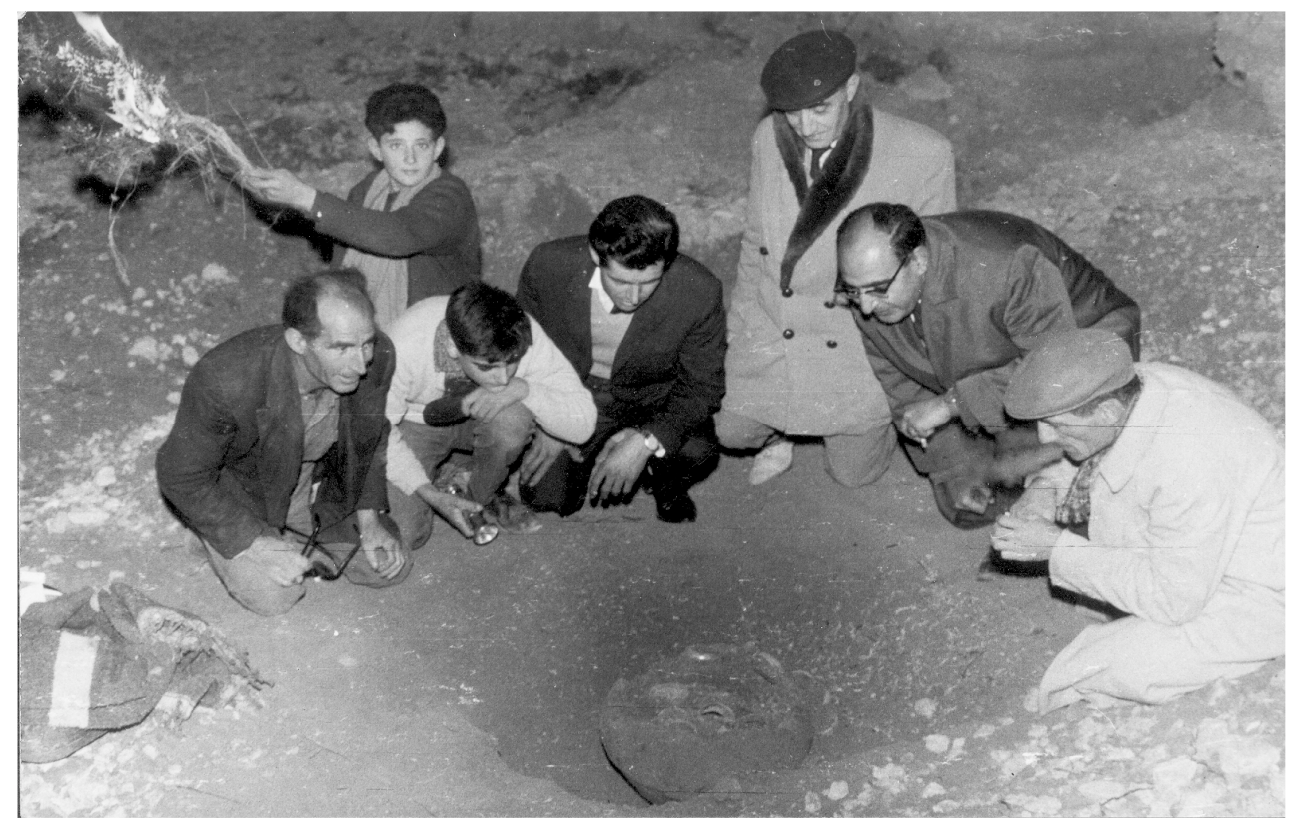

A

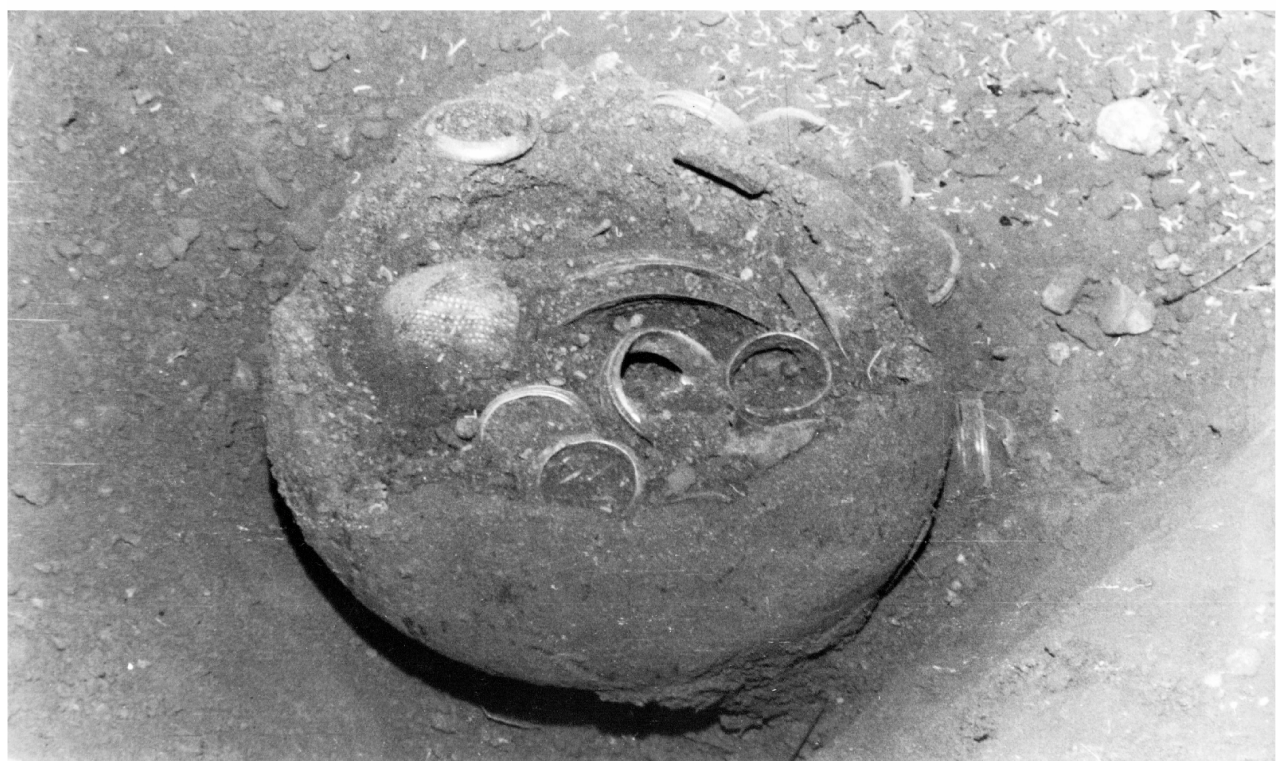

$\mathrm{B}$

Figura 1. A) Momento de la extracción del Tesoro de Villena, Alicante, durante la noche del 1 de diciembre de 1963 a la luz de antorchas y hogueras; B) Vasija que contenía el tesoro, antes de ser vaciada (Fotos: Flor Amat. Archivo del Museo Arqueológico “José María Soler" de Villena). 
de un edificio como el Tesoro de El Carambolo (Carriazo, 1959); o por la acción incontrolada de los buscadores de tesoros -y de problemas- como el caso del Tesoro de La Marina (Aranegui y Perea, 2000; Perea, 2006: figs. 13-15) que se encontró en Pic de l'Àguila, Dénia. Para no quedarse en la anécdota se han hecho esfuerzos desde una de las regiones que más tesoros arqueológicos ha proporcionado a la ciencia, Extremadura, con permiso de Galicia (Rodríguez Díaz et al., 2017). También se han conmemorado efemérides de hallazgos de tesoros importantes, como El Carambolo, aunque se hubieran encontrado en la basura (Bandera y Ferrer, 2010).

Las consecuencias del hallazgo de un tesoro tampoco suelen ser banales, y si no que se lo digan a Lord Carnarvon, víctima de la maldición del faraón por haber financiado las excavaciones de Howard Carter en la tumba KV-62, para regocijo de la prensa sensacionalista. El marido de la mujer en apuros, y un vecino que practicaba el voyerismo, sufrieron años de pleitos y encuestas judiciales, lo mismo que el cazatesoros que andaba por el monte con un detector de metales y no por una playa tranquila de Dénia donde se tropezara casualmente con el oro, como declaró en un principio. Pero el peor parado suele ser el propio tesoro, por el que todos los poderes institucionales y fácticos se pelean al intentar mostrarlo como trofeo. Así, el de Guarrazar quedó dividido entre dos países, Francia y España, y en tres museos diferentes. Lo mismo que el de Torredonjimeno, conservado en tres museos de distintas regiones españolas y muy dañado de andar de acá para allá. Pero lo normal son las expatriaciones. En el Museo Británico hay unos cuantos tesoros encontrados en la península ibérica, desde el torques triple de Sintra (Fig. 2A) que pesa 1255 gr al tesoro de Abía de la Obispalía, Cuenca, pasando por otros muchos (Enríquez, 2017); el Tesoro de Jávea, Alicante, acabó en Madrid, lo mismo que el de Aliseda, Cáceres; el de Berzocana, también cacereño y hallado en 1961, consiguió permanecer en Madrid utilizando, los interesados, triquiñuelas legalistas al borde de la legalidad; el hallador del de Villena tuvo que luchar denodadamente para que no se lo llevaran a la capital y conservarlo en su ciudad, aunque fuera en el cuartelillo de la Guardia Civil donde pasó años de reclusión para mayor seguridad, eso sí, siempre visitable -hoy tiene museo propio que ostenta el título de su descubridor, Museo Arqueológico "José María Soler". Y otros de triste destino, se les apagó algo de su brillo en el interior de alguna caja fuerte por la ausencia de presupuesto para exponerlos con seguridad. Pero la expatriación más espectacular es la del Tesoro Quimbaya (Perea et al., 2016) que hizo el viaje completo de Bogotá a Madrid como regalo del presidente colombiano a la reina regente doña María Cristina de Habsburgo-Lorena en 1892 (Fig. 2B).

Al contrario que en el caso de Indiana Jones, actualmente, las autoridades competentes se preocupan de los tesoros arqueológicos encontrados en el territorio de 


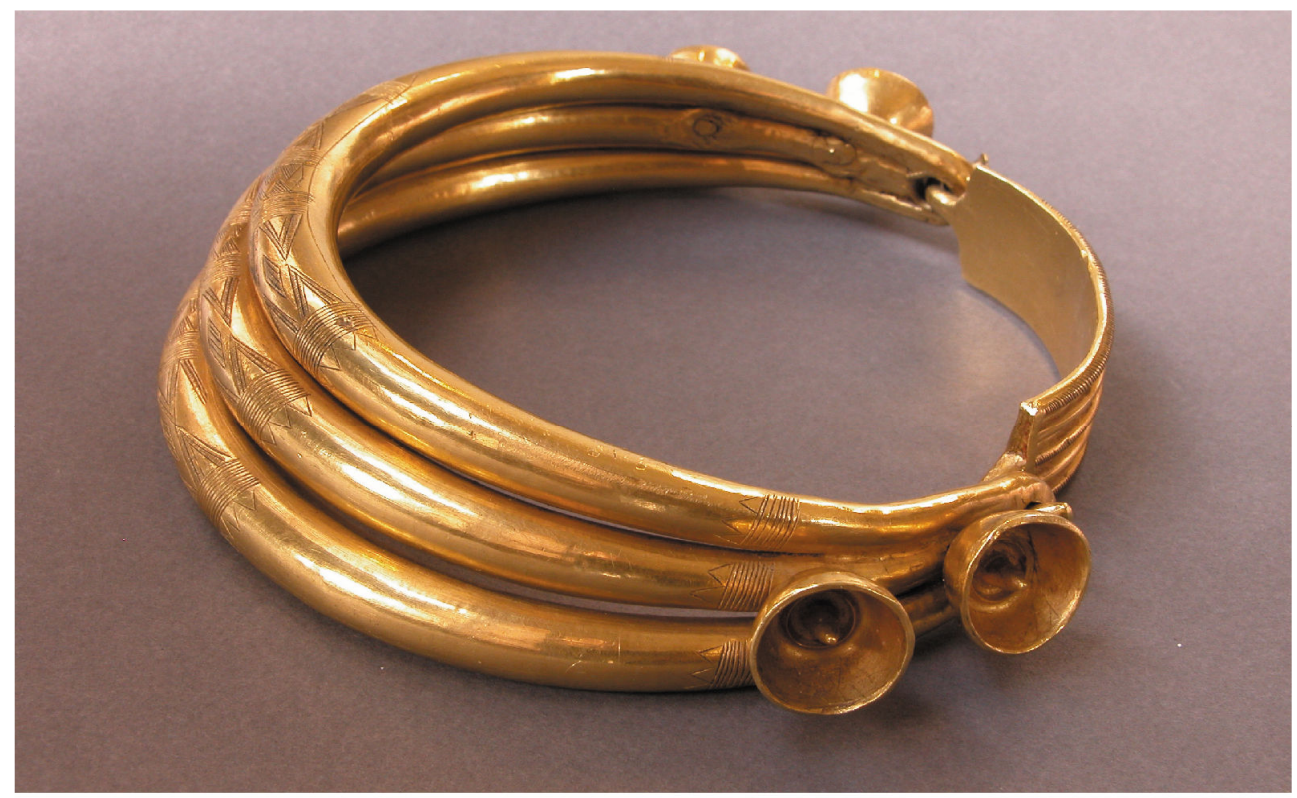

A
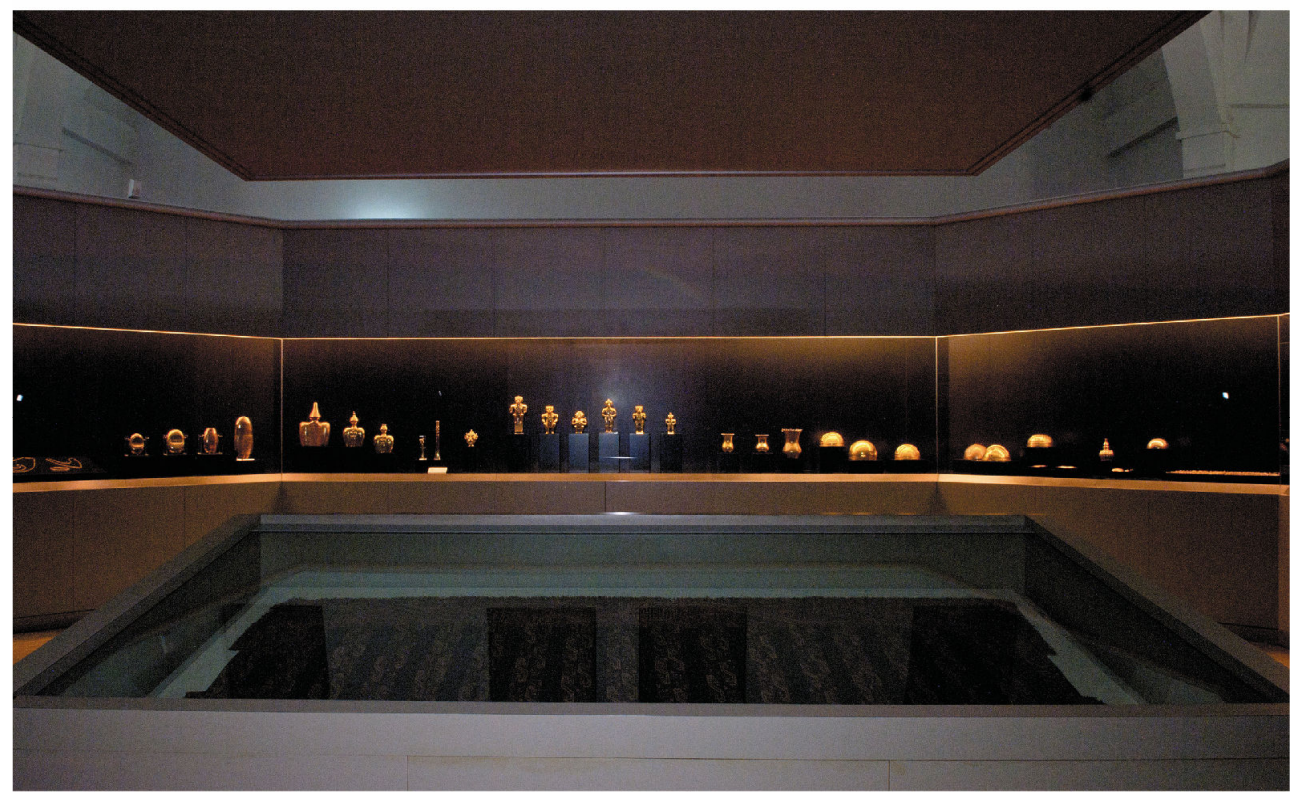

B

Figura 2. A) Torques de Sintra, Lisboa, Portugal, conservado en el Museo Británico desde 1900 (Foto: Alicia Perea, Archivo Au. CCHS-CSIC.); B) Vista panorámica de la sala donde se exhibe el Tesoro Quimbaya en el Museo de América, Madrid (Foto: Joaquín Otero Úbeda. Museo de América). 
sus tutelados, aunque no siempre con los mismos criterios e igual acierto. La Ley de Patrimonio Histórico Español de 1985 (Ley 16/1985, de 25 de junio, del Patrimonio Histórico Español. BOE $n^{\circ} 155$, de 29/06/1985. Última actualización publicada el $02 / 03 / 2019$ ) considera propiedad pública todo lo encontrado bajo tierra y penaliza el uso de detectores de metales en las excavaciones o búsquedas clandestinas. La legislación en Inglaterra es algo distinta; se rige por la Treasure Act 1996 Code of Practice (2nd Revision) para Inglaterra, Irlanda del Norte y Gales, en la que se establece que los tesoros encontrados bajo tierra son propiedad de la Corona y deben ser declarados a las autoridades en el plazo de 14 días posteriores al hallazgo; si el juez de instrucción declara que lo encontrado es efectivamente un tesoro (treasure trove) el hallador y en su caso el propietario de la tierra, tienen derecho a recibir una indemnización equivalente al precio de mercado de lo hallado. Como los detectores de metales son de libre uso, el Reino Unido se ha convertido en el paraíso de los buscadores de tesoros, y en el país que más hallazgos arqueológicos se recuperan al margen de las excavaciones arqueológicas regladas, hallazgos que se publican anualmente en los Treasure Annual Reports, del Department for Culture, Media and Sport.

Las regulaciones permisivas no deben escandalizarnos si recordamos que el huaquerismo -americanismo para el expolio de yacimientos arqueológicos en busca de tesoros- en los países latinoamericanos ha sido, desde la Conquista, un medio de vida (Valencia, 1989; Gamboa, 2002). Víctima del mismo expolio fue, por ejemplo, el territorio de la antigua Unión Soviética, sobre todo durante el siglo XVIII debido a la política territorial expansionista de los rusos por Siberia (Korolkova, 2017) hasta el punto de que Pedro I el Grande (1672-1725) tuvo que poner límites a una situación que estaba ya fuera de control, aunque sin mucho éxito. Este fue el germen del actual Hermitage (Korolkova, 2011, 2017).

\section{2. "EL TEMPLO MALDITO"}

La vida de los tesoros no es una vida tranquila, produce deslumbramientos físicos y mentales, y sus biografías son difíciles de desentrañar porque en ellas se entrecruzan los intereses personales y económicos de individuos e instituciones (Perea, 2001b). Desde el lado contrario, pero igualmente compleja, es la vida del estudioso que quiere acercarse a un tesoro para su investigación, y no por las comprensibles medidas de conservación y seguridad que deben establecer las instituciones depositarias, sino por un cierto recelo hacia la posibilidad de un cambio de estatus en el conocimiento establecido para entes tan rentables, es decir "remover las aguas tranquilas de la historia oficial" (Pavón et al., 2017: 242). Por ejemplo, el Tesoro de 
Guarrazar ha sido uno de los hallazgos que más revuelo internacional, académico, político y judicial ha levantado en nuestro país (Balmaseda, 2001), y, sin embargo, ha tenido que transcurrir siglo y medio para que se acometieran excavaciones en el lugar del hallazgo, con resultados más que brillantes (Rojas et al., 2017). Otro tanto ha ocurrido con la investigación de su propio contenido, es decir, las coronas y las cruces; desde los trabajos de Amador de los Ríos (1861) y Lasteyrie (1860), hasta 2001, nadie se preocupó de investigar en los objetos del tesoro por sí mismos, sino para reclamarlo o para utilizarlo en apoyo de los argumentos propios y desbaratamiento de los ajenos (Perea, 2001).

Ese recelo desaparece ocasionalmente cuando la institución, o las personas que hacen la institución, están realmente al servicio de la investigación. La exiliada Fíbula de Braganza (Fig. 3) es un objeto muy viajero que finalmente recaló en el Museo Británico, institución que ha acogido a tantos huérfanos y proscritos. Su destino la

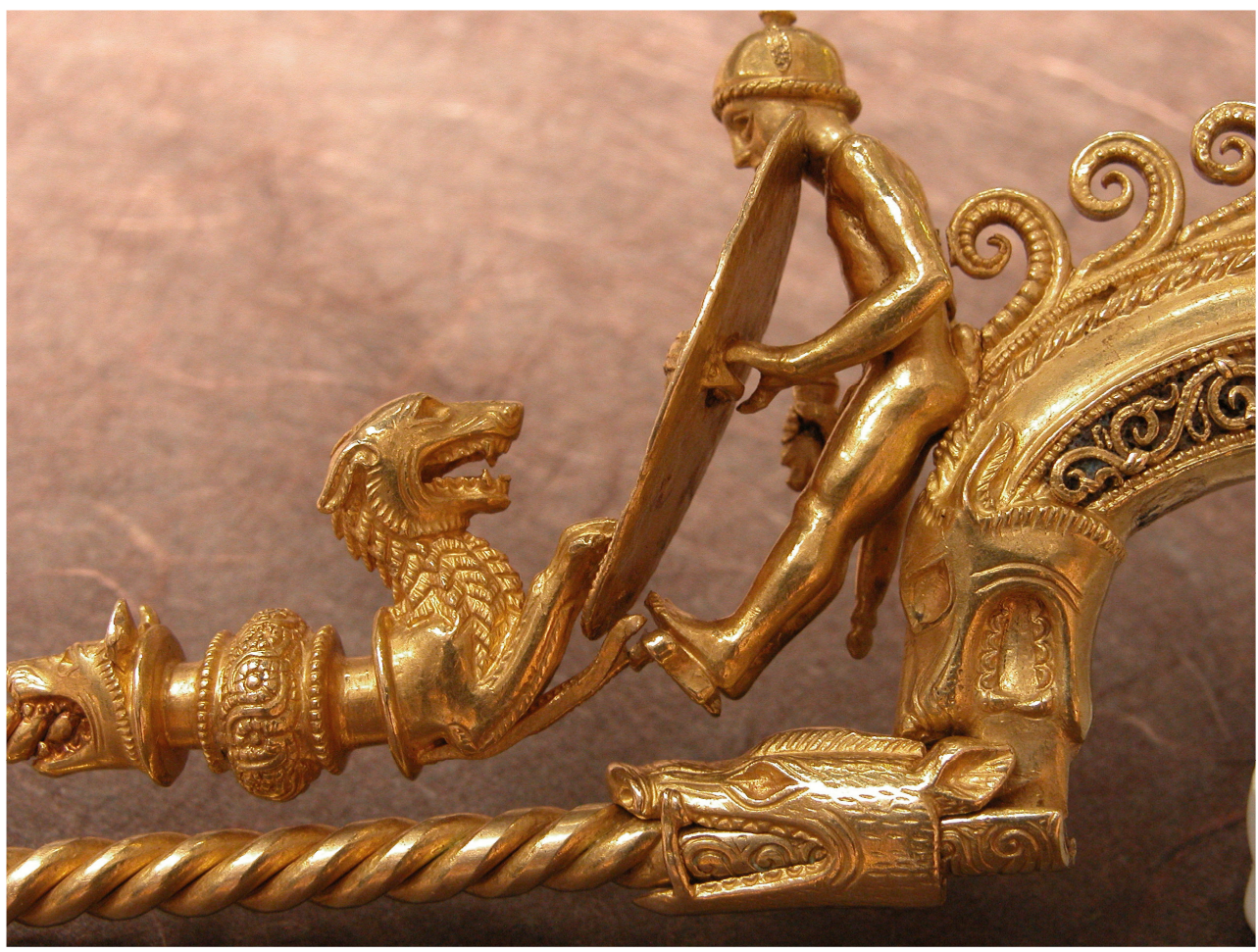

Figura 3. La Fíbula de Braganza fue comprada por el Museo Británico en pública subasta (Christie's, 25 de abril de 2001) por algo más de un millón de libras esterlinas, después de haber permanecido en depósito durante años

(Foto: Alicia Perea, Archivo Au. CCHS-CSIC). 
colocó en la sala que da acceso a los relieves del friso del Partenón -un corto pasillo algo oscuro- como si de un aperitivo se tratara antes de acceder al festín en la gran sala. En opinión de algunos (Perea et al., 2007), no era el sitio que le correspondía, y no por falta de méritos, porque algo de $\mathrm{ADN}$ griego debe tener este opulento broche helenístico, sino porque sus hermanos ibéricos lo echaban en falta. Así pues, volvió a la Península en una breve visita de familia que resultó fructífera en diálogo y discusión académica de la buena (Perea, 2011), aunque continúa estando en el sitio que no le corresponde. Otra breve visita familiar fue la que hizo en 2009 el Tesoro de Abía de la Obispalía, Cuenca, al MARQ de Alicante, para ser visto en la exposición "En los confines del Argar. Una cultura de la Edad del Bronce en Alicante" (Hernández, 2009). Estos regresos temporales deberían repetirse más a menudo.

Recelos los despertados por el Tesoro de Aliseda desde su descubrimiento en 1920, en una coyuntura histórica, política y económica difícil para la pobre gente de este país, hasta hace poco más de una década en la que se pudo empezar a recuperar lo que quedaba del contexto arqueológico del hallazgo (Rodríguez Díaz et al., 2019; Perea, 2020) y de su intrahistoria, una recuperación que ha cambiado el panorama y la perspectiva de este conjunto emblemático al que siempre se vuelve. En este caso, el cambio de estatus se demoró, pero ha merecido la pena. Lo mismo ha ocurrido con El Carambolo; las excavaciones regladas en el yacimiento tardaron algo más de medio siglo, pero fueron capaces de dignificar el basurero donde en 1958 se encontró el tesoro (Fernández Flores y Rodríguez Azogue, 2005; Fernández Flores et al., 2020), al fin y a la postre se trataba de un basurero sagrado y monumental, y no un fondo de cabaña como se quiso ver en la apresurada excavación de Carriazo inmediatamente después del hallazgo.

Hablando de recelos y recuperaciones, existe un caso que no podemos obviar, los tesoros castreños, rodeados de lluvia, bruma y misterio, como el clima y la tierra que los acogió. Desde el tesoro desencantado de As Silgadas (Domato y Comendador, 1998), hasta los torques y arracadas (Barril y Rodero, 2002; Balseiro, 2018), han pasado dos siglos de investigación que se sustancian en la vuelta a los orígenes donde reside toda la verdad, es decir, al objeto, su contexto y a la historiografía que les rodea, con el riesgo real de desenmascarar tesoros que nunca han sido (García Vuelta, 2001 y 2007). También ayuda la arqueología científica iquién hubiera dicho que llegaríamos a tener fechas radiocarbónicas para los tesoros descontextualizados! pues ya está ocurriendo (Armada y García Vuelta, 2015).

El cambio de estatus y la recuperación de contextos no es el único quiebro en la agitada vida de los tesoros, sino que están aprendiendo a vivir con nuevas biografías y 
compañeros de viaje. La excavación en los archivos privados e institucionales ha resultado sorpresiva y rentable para unos conjuntos procedentes de colecciones decimonónicas, que el tiempo y la desidia habían barajado para hacer la vida del investigador más entretenida (García Vuelta y Perea, 2001; Galán, 2017; García Vuelta, 2018 y 2019).

\section{3. "LA CALAVERA DE CRISTAL"}

Aliseda es el tesoro al que siempre se vuelve, como decía. Es el inicio de nuevas vías de estudio y el cuestionamiento de otras en un mundo, el de la arqueología y los arqueólogos, pequeño, competitivo y ocasionalmente mezquino, como no podía ser de otra manera puesto que está integrado por seres humanos.

Poca cosa se sabía entonces, 1920, de lo que actualmente llamamos periodo Orientalizante, tampoco de Tartessos fuera lo que fuere, salvo por lo que decían unas fuentes dispersas y los hallazgos de unas excavaciones depredadoras, aunque legales, en los arrabales de Cádiz entre 1912 y 1934 que se hacían eco de los continuos hallazgos en una ciudad en crecimiento, sobre todo pequeños objetos de oro, pero también un extraordinario sarcófago antropoide masculino aparecido en 1887 con motivo de las obras de instalación de la Exposición Marítima Nacional. Según el decir popular de la época no había familia en Cádiz que no tuviera una joya de oro fenicia de lo que entonces era un juego y hoy llamaríamos expolio; expolio sancionado por la ley de 1911 que permitía al financiador de la excavación quedarse con parte del material exhumado (Perea, 1986), tal y como estaba ocurriendo en la necrópolis fenicio-púnica del Puig des Molins, Ibiza, por los mismos años, lo que provocó el litigio entre los arqueólogos Vives y Escudero y Román Ferrer por su derecho a excavar en dicho yacimiento, litigio en el que participó, en un momento dado, el académico José Ramón Mélida (Fernández Gómez, 2020). Así pues, Mélida (1921) no tuvo otro recurso argumental que considerar fenicio el tesoro recién aparecido, compuesto por casi 300 piezas de oro, además de otras en plata y vidrio, desconocidas hasta entonces y sobre todo ¡encontradas en un pueblo perdido de Cáceres a más de $300 \mathrm{~km}$ de distancia de Cádiz! La teoría de que formaban parte del ajuar funerario femenino de una sepultura bajo túmulo -y no sin argumentos- se impuso entre la mayoría de los investigadores posteriores, así como una serie de prejuicios de larga vida historiográfica, a saber, que las piezas de oro de Aliseda no pudieron salir de manos de unos indígenas orientalizados pero incapaces de fabricar obras tan complejas y de tal calidad, por tanto, eran piezas importadas y sólo Cádiz cumplía las condiciones para producir obras de esa categoría -aunque Cádiz no había dado, ni daría después, ni dará nunca, objetos semejantes. La idea de la incapacidad del indígena ha sido una 
constante en la investigación sobre la colonización y las relaciones coloniales en nuestro país, hasta tal punto que parecía reflejar inconfesables complejos que el tiempo y los cambios de paradigma en la investigación arqueológica han curado definitivamente. Tendría que pasar casi medio siglo hasta que constructos como hinterland y periferia se abrieran paso.

La llamada diadema de Aliseda no es la primera de su especie que había aparecido en la Península. El magnífico ejemplar del Tesoro de Jávea, Alicante, fue hallado en 1905, y fue estudiado igualmente por Mélida (1905), sin embargo, no se relacionaron en un primer momento, puesto que el ejemplar alicantino, además de estar completo y ser más grande consecuentemente- presentaba un estilo claramente grequizante y no fenicio. No sabemos si el platero al que se encargó la reconstrucción de la diadema -y del cinturón- tuvo en cuenta este ejemplar, probablemente sí, pero quedó patente que el de Aliseda era un objeto incompleto, y así ha permanecido hasta nuestros días, como un pequeño engendro -criatura informe que nace sin la proporción debida según definición de la RAE. Hoy sabemos que la mal llamada diadema de Aliseda es el ejemplar más antiguo de una larga estirpe -Cortijo de Ébora, La Puebla de los Infantes, Mairena del Alcor, Giribaile, Las Guijas- que se prolonga hasta el siglo III a.C. (Perea, 1996 y 1997). Y digo mal llamada porque no existe ninguna evidencia de que este tipo de objeto fuera llevado sobre la frente o la cabeza, y consecuentemente propuse en diversas ocasiones rebautizar el tipo como Banda de Extremos Triangulares, que me parecía más aséptico, con escaso éxito (Perea, 2010). Las primeras denominaciones en arqueología mandan mucho y, una vez establecido el título, nadie es capaz de cambiarlo por más que las circunstancias y el paradigma lo requieran. Lo mismo ocurrió con el único tesoro que no se conoce por tal nombre sino por el familiar de Candelabros de Lebrija (Perea et al., 2003), aunque no sean tales candelabros.

El cinturón, por el contrario, no suscitó discusión alguna. Una magnífica pieza, del tamaño adecuado, completa o casi completa, con una iconografía que no dejaba mucho espacio a la imaginación: el dominio del hombre sobre la bestia, en este caso un león. Su carácter masculino estaba fuera de toda duda ¿quién azota al niño díscolo en la escuela? A nadie se le imagina una maestra zurrando con su cinturón al desobediente. Son imágenes masculinas, recias, que estaban en el imaginario de todos los de la época -afortunadamente ya se están perdiendo. El cinturón es el símbolo del poder masculino por antonomasia y así lo entendieron todos, porque con él se fustiga ¿por qué, si no, el atributo de Indiana Jones fue un látigo?

Más discutible y discutidos fueron los múltiples colgantes amuleto que se reconstruyeron ensartándolos en varios hilos. El modelo estaba claro, al menos para el tipo 
con forma de lengüeta, que aparecía en la fila inferior de los tres grandes collares de la Dama de Elche. Luego vendrían otras, todas con algún collar de grandes lengüetas, pero entonces sólo se conocía a la de Elche y, a pesar de ello, la referencia para estos tesoros fueron más bien las damas del Cerro de los Santos, con su larga historia de exilios y engaños. La diferencia de escala, las formas hipertróficas y, sobre todo, el cambio de material, oro por piedra, no permitieron hacer las sinapsis adecuadas. Ahora sabemos que, como en casi todo, Aliseda fue el modelo que marcó la pauta.

De la colección de anillos, un repertorio tipológico bien expresivo de la pequeña iconografía mediterránea, pudieron ser utilizados tanto por un hombre como por una mujer, pero eso no es lo que más nos interesa, sino las composiciones simbólicas del árbol de la vida que flanquean algunos de los engastes (Fig. 4), las máscaras, los escarabeos, la barca solar, y el jinete, junto a la escena de adoración de la palmeta grabada en el reverso de la amatista engastada como colgante arriñonado, todos estos motivos fueron elegidos y seleccionados para los personajes destinados a poseer las joyas, no hay casualidad en ello. El anillo forma parte del personaje porque se poseen mutuamente (Perea y Olmos, 2018). Enlazando con esta última escena ceremonial hay que mencionar la patera de oro, otro objeto que está destinado al personaje que oficia la libación, hombre o mujer. Y el gran aro o torques, del que mucho se ha especulado y poco establecido, podría integrarse dentro de este set ritual.

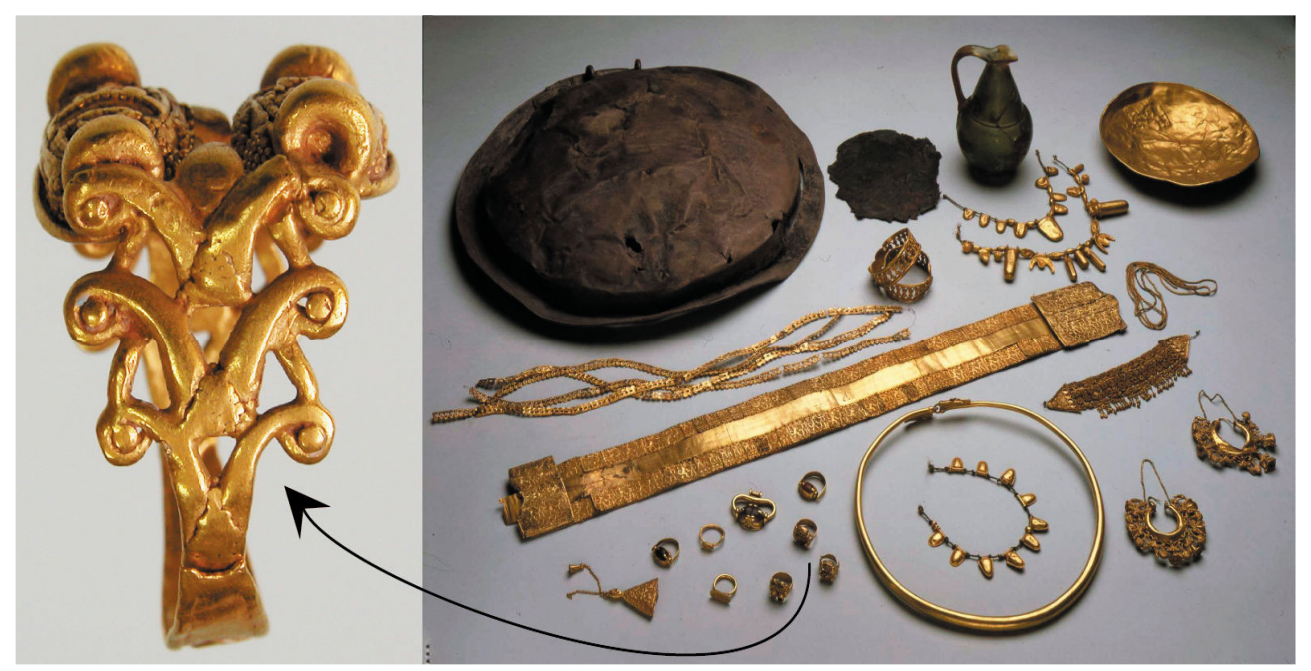

Figura 4. Lateral de uno de los anillos del conjunto de Aliseda, Cáceres, que muestra un árbol de la vida. El desgaste por uso ha borrado casi totalmente el granulado con que se adornaba la base triangular de los roleos (Fotos: Alicia Perea, Archivo Au. CCHS-CSIC y MAN). 
Para el final dejo las arracadas y los brazaletes. Estos últimos sí parecen de uso femenino por el tamaño, pero las arracadas no tienen género en un mundo exótico y exuberante. En los relieves asirios siempre se representa al rey, de perfil, con vestimenta ceremonial y una arracada con crestería en la oreja visible (Maxwell-Hyslop, 1971: fig. 127, láms. 220-222). Las de Aliseda llevan al límite la expresión de una naturaleza en plenitud. Lo mismo que los dos centenares de pequeños colgantillos y cadenas que estaban preparados para ser cosidos a un manto o vestido.

\section{4. "LA ÚLTIMA CRUZADA"}

Comenzaba esta contribución con una cita cinematográfica para conmemorar el centenario del Tesoro de Aliseda, y quiero terminarla con una cita literaria que tiene conexión con el cine; fue la base del guion de una película dirigida con desgana por Antonio Mercero en 1988. Me refiero a la novela El Tesoro de Miguel Delibes (1985) construida a partir del relato del hallazgo del Tesoro de Arrabalde, Zamora,



Figura 5. Dos fíbulas anulares pertenecientes al primer Tesoro de Arrabalde, Zamora (Foto: Alicia Perea, Archivo Au. CCHS-CSIC). 
vivido en primera persona por su hijo, el arqueólogo, una auténtica aventura a la que Spielberg hubiera sacado mejor partido. Pero es mejor volver a una novela en la que hábilmente el autor pone en situación límite a sus personajes, que se retratan a sí mismos. El hallazgo actúa como una catarsis en la que frustraciones y esperanzas salen a la superficie y se manifiestan con muy distintas reacciones.

El primer Tesoro de Arrabalde (Fig. 5), porque hubo dos hallazgos en $1980 \mathrm{y}$ en 1987, puede ser comparado con el de Aliseda, y no por el entorno histórico y cronológico, castreño-astur-celtíbero uno y orientalizante el otro, sino por la cantidad y variedad de objetos encontrados, en oro y plata (Delibes de Castro, 2017; Esparza, 2017); arracadas, espirales, sortijas, fíbulas, torques, brazaletes, pulseras y elementos de vajilla, todas piezas en uso y utilizadas que desataron la codicia de los paisanos del entorno y el interés de arqueólogos y autoridades por intentar lucrarse unos y recuperarlas para la historia los otros. Es un relato que todos hubiéramos querido borrar de nuestro recuerdo, aunque la búsqueda clandestina de tesoros es un hecho demasiado frecuente en la Meseta norte, sirva de ejemplo el caso de los tres tesorillos de Padilla de Duero, Valladolid (Delibes de Castro et al., 1993). Afortunadamente, tanto Aliseda como Arrabalde y Padilla forman parte hoy de nuestro patrimonio histórico recuperado.

Hemos abusado de las palabras, hemos suscitado la codicia y el engaño, pero también hemos pagado las consecuencias. Debemos seguir, los arqueólogos, comprometidos en la lucha contra la desinformación, y erradicar prejuicios y desigualdades. Que así sea.

\section{BIBLIOGRAFÍA}

AMADOR DE LOS RÍOS, J. (1861): El arte latino-bizantino en España y las coronas visigodas de Guarrazar. Ensayo histórico-crítico, Madrid.

ARANEGUI, C. y PEREA, A. (2000): "Villena y La Marina. Dos depósitos de joyas relacionados con la cultura tartésica. El marco de la Historia”, en J. C. Lledó y R. Azuar, (coords.): Argantonio Rey de Tartessos, Alicante.

ARMADA, X. L. y GARCÍA VUELTA, O. (2015): "Dating Iron Age goldwork: first direct AMS 14C results from Northwestern Iberia". Trabajos de Prehistoria, 72 (2), pp. 372-382.

BALMASEDA L. (2001): "De la historia del hallazgo y la arqueología de Guarrazar", en A. Perea (ed.): 2001a, pp. 63-79.

BALSEIRO, A. (ed.). (2018): A Colecciónde de Ourivesaría Antiga do Museo Provincial de Lugo, Lugo. 


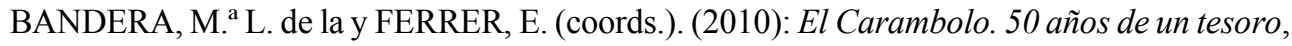
Sevilla.

BARRIL, M. y RODERO, A. (dirs.). (2002): Torques. Belleza y Poder, Madrid.

CARRIAZO, J. de M. (1959): "Las joyas y las excavaciones del Carambolo", Archivo Hispalense, XXX, pp. 153-162.

DELIBES, M. (1985): El Tesoro, Barcelona.

DELIBES DE CASTRO, G. (2017): "De nuevo sobre los tesoros prerromanos de Arrabalde (Zamora)”, en A. Rodríguez Díaz, I. Pavón y D. M: Duque Espino (eds.), pp. 319-346.

DELIBES DE CASTRO, G., ESPARZA, A., MARTÍN, R. y SANZ, C. (1993): “Tesoros celtibéricos de Padilla de Duero", en F. Romero, C. Sanz y Z. Escudero (eds.): Arqueología Vaccea. Estudios sobre el mundo prerromano en la Cuenca Media del Duero, Valladolid, pp. 397-470.

ESPARZA, A. (2017): "Un contexto para los tesoros de Arrabalde: el castro de Las Labradas", en A. Rodríguez Díaz, I. Pavón y D. M: Duque Espino (eds.), pp. 347-364.

DOMATO, X. M. y COMENDADOR, B. (1998): El Tesoro desencantado. As Silgadas (Caldas de Reis, Concello de Caldas de Reis, Santiago.

ENRÍQUEZ, J. J. (2017): “Tesoros que se fueron. Piezas áureas del Calcolítico y Edad del Bronce que migraron de Extremadura", en A. Rodríguez Díaz, I. Pavón y D. M: Duque Espino (eds.), pp. 87-123.

FERNÁNDEZ FLORES, A., CASADO, M. y PRADOS, E. (2020): "Primeros vestigios de la colonización fenicia en El Carambolo. El edificio inicial (Carambolo V), función y cronología”, en J. L. López Castro (ed.): Entre Utica y Gadir. Navegación y colonización fenicia en el Mediterráneo Occidental a comienzos del I milenio a.C., Granada, pp. 201-228.

FERNÁNDEZ GÓMEZ, J. H. (2020): "El pleito entre Vives y Escudero y el Estado por las excavaciones en la necrópolis del Puig des Molins (Eivissa)”, Fites, 20, pp. 17-31.

FERNÁNDEZ FLORES, A. y RODRIGUEZ AZOGUE, A. (2005): "El complejo monumetal del Carambolo Alto, Camas (Sevilla). Un santuario orientalizante en la paleodesembocadura del Guadalquivir", Trabajos de Prehistoria, 62 (1), pp. 111-138.

GALÁN, E. (2017): “Trabajos de oro perdidos. Noticia de dos antiguos hallazgos áureos y su relación con el Museo Arqueológico Nacional”. Boletín del Museo Arqueológico Nacional, 36, pp. 35-54.

GAMBOA, P. (2002): El Tesoro de los Quimbayas. Historia, Identidad y Patrimonio, Bogotá. GARCÍA VUELTA, O. (2001): "El conjunto de Cangas de Onís: arqueología del oro castreño asturiano". Trabajos de Prehistoria, 58 (2), pp. 109-127.

(2007): Orfebrería Castreña del Museo Arqueológico Nacional, Madrid.

(2018): "Estudios documentales e investigación de la orfebrería castreña en Asturias: aportaciones sobre las piezas de la colección Soto Cortés”, en A. Carretero Pérez, C. Papí y G. Ruíz (eds.): Actas del V Congreso Internacional de Historia de la Arqueología-IV 
Jornadas de Historiografía SEHA-MAN. Arqueología de los museos: 150 años de la creación del Museo Arqueológico Nacional, Madrid, pp. 1.397-1.410.

(2019): "Notas sobre hallazgos desaparecidos de orfebrería antigua en Asturias: el torques de Valentín (Coaña) y los conjuntos de Villabona (Tineo) y Luces (Lastres, Colunga)", en A. Villa y F. Rodríguez (coords.): Arqueología Castreña en Asturias. Contribuciones a la conmemoración del Día García y Bellido. Oviedo, pp. 43-72.

GARCÍA VUELTA, O. y PEREA, A. (2001): "Las diademas-cinturón castreñas: el conjunto con decoración figurada de Moñes (Villamayor, Piloña, Asturias)", Archivo Español de Arqueología, 74, pp. 3-23.

HERNÁNDEZ, M. S., LÓPEZ, J. A. y SOLER, J. A. (2009): En los confines del Argar. Una cultura de la Edad del Bronce en Alicante en el centenario de Julio Furgús, Alicante.

KOROLKOVA, E.F. (2011): "La primera colección arqueológica de Rusia", Ermitage. Tesoros de la Arqueología Rusa en el MARQ, Alicante, pp. 41-45.

KOROLKOVA, E.F. (2017): "The Siberian Collection of Peter the Great”, en S. J. Simpson y S. Pankova, (eds.): Scythians, warriors of ancient Siberia, Londres, pp. 34-40.

LASTEYRIE, F. de. (1860): Description du Trésor de Guarrazar, accompagné des recherches sur toutes les questions archéologiques qui s'y rattachent. Gide Éditeur. Paris.

MAXWELL-HYSLOP, K. R. (1971): Western Asiatic Jewellery c. 3000-612 B.C., Londres.

MÉLIDA, J. R. (1905): “El tesoro ibérico de Jávea”, Revista de Archivos, Bibliotecas y Museos, XIII, pp. 366-373. (1921): "El tesoro de Aliseda. Noticia del tesoro en particular y de la joyería fenicia en general", Boletín de la Sociedad española de Excursiones, XXIX, pp. 96-124.

PAVÓN, I., RODRÍGUEZ, A. y DUQUE, D. M. (2017): “El Tesoro de Aliseda: de la 'Historia oficial' a la intrahistoria”, en A. Rodríguez Díaz, I. Pavón y D. M: Duque Espino (eds.), pp. 241-275.

PEREA, A. (1986): “La Orfebrería Púnica de Cádiz”, en G. del Olmo y M. a E. Aubet (dir.): Los Fenicios en la Península Ibérica, Sabadell, pp. 295-322.

(1996): "La orfebrería peninsular en el marco del arcaismo mediterráneo: dos perspectivas", en

R. Olmos y P. Rouillard (eds.): Formes Archaïques et Arts Ibériques, Madrid, pp. 95-109. (1997): "El busto en piedra aparecido hace un siglo en La Alcudia", en R. Olmos, y T. Tortosa (eds.): La Dama de Elche. Lecturas desde la diversidad, Madrid, pp. 145-157.

(2001a) (ed.): El Tesoro visigodo de Guarrazar, Madrid.

(2001b): "Biografías de escondrijos y tesoros prehistóricos en la Península Ibérica", en M. S. Hernández (ed.): ...Y acumularon Tesoros. Mil años de historia en nuestras tierras, Alicante, pp. 15-27.

(2006): "Entre la metáfora y el mito. La representación simbólica de lo femenino en la sociedad ibérica", MARQ. Arqueología y Museos, 01, pp. 49-68.

(2009) (ed.): El Tesoro visigodo de Torredonjimeno, Madrid. 
(2010): "Las joyas de la Dama de Baza: un espacio femenino", en T. Chapa e I. Izquierdo (coords.): La Dama de Baza. Un viaje femenino al más allá, Madrid, pp. 201-209.

(2011) (ed.): La Fíbula Braganza. The Braganza Brooch, Madrid.

(2020): Recensión: Rodríguez Díaz, A., Pavón, I. y Duque, D. M., 2019, Trabajos de Prehistoria, 77 (1), pp. 191-193.

PEREA, A., ARMBRUSTER, B., DEMORTIER, G. y MONTERO, I. (2003): "Tecnología atlántica para dioses mediterráneos. Los 'candelabros' de oro tipo Lebrija". Trabajos de Prehistoria, 60 (1), pp. 99-114.

PEREA, A. y OLMOS, R. (2018): “El poder en sus manos”, en L. Prados, C. Rueda y A. Ruíz (eds.): Bronces Ibéricos. Una historia por contar: libro homenaje al Prof. Gérard Nicolini, Jaén, pp. 535-566.

PEREA, A., VERDE, A. y GUTIÉRREZ, A. (2016): El Tesoro Quimbaya. CSIC. Museo de América. Madrid.

PEREA, A., WILLIAMS, D. y OLMOS, R. (2007): El Héroe y el Monstruo, Madrid.

RÍOS, J. A. de los. (1861): El Arte latino-bizantino en España y las coronas visigodas de Guarrazar, Madrid.

RODRÍGUEZ DÍAZ, A., PAVÓN, I. y DUQUE, D. M. (2017) (eds.): Historias de Tesoros, Tesoros con Historia, Cáceres.

(2019): El Tesoro de Aliseda, cien años después. En el laberinto de sus historias, Barcelona.

ROJAS, J. M., EGER, CH., CATALÁN, R. y GARCÍA VACAS, L. (2017): "Wo einst goldene Kronen und Kreutze verborgen wurden. Neue Ausgrabungen in Guarrazar. Vorbericht zu den Kampagnen 2013 und 2014”, en S. Panzram (ed.): Oppidum-Civitas-Urbs. Städteforschung auf der Iberischen Halbinsel zwischen Rom und al-Andalus, Berlín.

SOLER, J.M. (1965): El Tesoro de Villena, Madrid.

VALENCIA, A. (1989): "La guaquería en el viejo Caldas", Boletín del Museo del Oro, 23, pp. 60-75.

Alicia PEREA CAVEDA http://orcid.org/0000-0002-8002-2757 alicia.perea@cchs.csic.es 